\title{
EFEKTIVITAS PEMBERLAKUAN KEBIJAKAN MORATORIUM KAPAL EKS ASING DAN TRANSHIPMENT TERHADAP KINERJA USAHA PENANGKAPAN IKAN
}

\section{Effectivity of Ex Foreign Ships Moratorium and Transhipment Policy on Captured Fisheries Business Performance}

\author{
'Yayan Hikmayani, Rikrik Rahadian, Nurlailii dan Rizky Muhartono \\ Balai Besar Penelitian Sosial Ekonomi Kelautan dan Perikanan \\ Gedung Balitbang KP I Lt. 4 \\ Jalan Pasir Putih Nomor 1 Ancol Timur, Jakarta Utara \\ "email: yayanhikmayani @yahoo.ca
}

Diterima 20 Juli 2015 - Disetujui 8 November 2015

\begin{abstract}
ABSTRAK
Penelitian untuk melihat efektivitas kebijakan moratorium kapal eks asing dan transhipment telah dilakukan pada Bulan Maret 2015. Tujuan penulisan makalah ini yaitu untuk melihat pengaruh langsung dari pemberlakuan kebijakan tersebut terhadap kinerja usaha perikanan. Lokasi penelitian dilakukan di tempat pendaratan ikan bagi kapal-kapal ikan yang terkena dampak, seperti di Bitung dan DKI Jakarta. Metode pengambilan responden dilakukan secara terpilih, yaitu instansi terkait : pelabuhan perikanan, pengawas perikanan, serta pelaku usaha. Pengambilan data terdiri dari data primer dan data sekunder. Analisis data dilakukan secara tabulasi dan diolah menggunakan statistik sederhana untuk menjawab tujuan penelitian. Hasil penelitian menunjukkan bahwa kebijakan yang telah diimplementasikan dilihat dari tujuan untuk mengurangi illegal fishing dianggap secara nyata cukup efektif. Hal ini ditunjukkan dengan menurunnya jumlah illegal fishing. Namun demikian, di sisi lainnya kebijakan tersebut dinilai tidak efektif bagi peningkatan kinerja usaha penangkapan skala besar dan telah cukup efektif untuk meningkatkan kinerja usaha penangkapan ikan skala kecil. Diharapkan keijakan ini akan diikuti oleh perbaikan sistem monitoring yang baik dari pihak pemerintah agar pemberlauan kembali kapal transhipment tidak digunakan untuk kegiatan illegal fishing, namun membangkitkan inerja usaha perikanan dari hulu ke hilir yang berkembang di Indonesia.
\end{abstract}

Kata Kunci: efektivitas, moratorium, kapal eks asing dan transhipment

ABSTRACT

This study is aimed at investigating the effectiveness of the moratorium and transhipment policies. The investigation was conducted on March 2015 in several fish-landing sites which were heavily affected by the two policies, such as Bitung and DKI Jakarta, through surveys to acquire both primary and secondary data needed, with purposively chosen respondents. The data acquired were then descriptively analyzed and tabulated, which resulted in the finding that the policies implemented thus far had been very effective in suppressing illegal fishing. Despite their effectiveness, big fisheries business owners in jakarta complained that the transhipment policy had caused them quite a big loss through the effect of a hiking fishing cost as well as reducing catch. While the big fisheries business owners in Bitung complained that both policies had caused them much bigger lost by reducing the supply of input. But different stories were received by small scale fishers who felt that they had been getting more fish than they usually had. Therefore, the moratorium policies need to be continued while the government preparing to alter the transhipment policy - especially in the enhancement of the monitoring system - so that the policies may suppress illegal fishing while creating a condition for growth of fishery businesses from top to bottom in Indonesia.

Keywords: effectiveness, moratorium, transhipment and ex-foreign ships 


\section{PENDAHULUAN}

Kegiatan Illegal, Unreported, Unregulated (IUU) Fishing di Indonesia sudah sangat merugikan rakyat dan bangsa Indonesia. Menurut Jaelani Aq dan Udiyo B. (2014) bahwa illegal fishing dilakukan oleh orang asing atau pun oleh warga negara Indonesia sendiri dengan berbagai cara yang tidak sesuai dengan UndangUndang Nomor 31 Tahun 2004 jo. Undang-Undang Nomor 45 Tahun 2009 tentang Perikanan. Kerugian negara akibat illegal fishing mencapai 300 trilyun rupiah pertahun, yaitu dengan memperhitungkan tingkat kerugiannya yang mencapai $25 \%$ dari total potensi perikanan Indonesia (Anonim, 2014). Kerugian tersebut berdampak merugikan negara dan mengancam kelestarian sumber daya kelautan dan perikanan. (Marlyna dan Riza, 2013) .

Kegiatan IUU Fishing telah banyak merugikan negara RI. Kerugian yang diakibatkan baik secara sosial, ekonomi,politik dan lingkungan. Sunyowati (2014) menyatakan dampak ekonomi, setiap tahun diperkirakan Indonesia mengalami kerugian akibat IUU Fishing sebesar Rp. 101.040 trilliun/tahun. Kerugian ekonomi lainnya adalah hilangnya nilai ekonomis dari ikan yang dicuri, pungutan hasil perikanan (PHP) akan hilang, dan subsidi BBM dinikmati oleh kapal perikanan yang tidak berhak. Selain itu, Unit Pengelolaan Ikan (UPI) kekurangan pasokan bahan baku sehingga melemahkan upaya pemerintah untuk mendorong peningkatan daya saing produk perikanan. Dampak politik sebagai salah satu pemicu konflik atau ketegangan hubungan diplomatik diantara negara-negara, mengganggu kedaulatan Negara Kesatuan Republik Indonesia (NKRI), menimbulkan citra negatif, karena beberapa negara menganggap kita tidak mampu mengelola sumber daya kelautan dengan baik. Dampak sosial rawannya terjadi konflik/sengketa diantara para nelayan tradisional antar negara dan pemilik kapal pukat/ trawl. Dampak lingkungan kejahatan pencurian ikan yang berakibat pada rusaknya sumberdaya kelautan dan perikanan. Alat tangkap yang digunakan dalam bentuk bahan beracun yang akan merusak terumbu karang (alat tangkap ikan yang tidak ramah lingkungan), sebagai tempat berpijahnya ikan, akan berakibat makin sedikitnya populasi ikan dalam suatu perairan tertentu, atau menangkap menggunakan alat tangkap ikan skala besar (seperti trawl dan pukat harimau) yang tidak sesuai dengan ketentuan dan keadaan laut Indonesia secara semena-mena dan eksploitatif sehingga menipisnya sumberdaya ikan. Hal ini akan mengganggu keberlanjutan perikanan.
Dari sisi kedaulatan praktek IUU Fishing telah mengancam kedaulatan RI karena di beberapa lokasi perairan Indonesia bebas berkeliaran pelaku pencurian ikan yang menyebabkan ketidaknyamanan berusaha.

Sudah banyak dilakukan kebijakan yang tujuannya untuk mengurangi bahkan memberantas aksi pencurian ikan tersebut di era pemerintahan sebelumnya. tapi ternyata belum memberikan efek jera dan dapat berdampak banyak pada berkurangnya kegiatan IUU Fishing. Untuk itu, diperlukan upaya yang lebih serius dari pemerintah untuk membuat efek jera terhadap pelaku. Menurut Damanik (2014) bahwa illegal fishing dalam hal ini merupakan tindak kejahatan yang sudah nyata dan seharusnya ditindak tegas karena sudah memberikan kerugian yang sangat besar terhadap semua sektor kehidupan masyarakat Indonesia.

Pemerintahan era Presiden Jokowi dengan salah satu programnya yaitu "poros maritim" yang memperlihatkan bahwa keberadaan laut menjadi sangat penting. Bahkan kegiatan yang dilakukan yang bertujuan pada upaya keberlanjutan serta kedaulatan menjadi perhatian penting yang dilaksanakan di era pemerintahannya. Salah satu kementerian yang bertanggungjawab terhadap pengelolaan sumberdaya kelautan dan perikanan yaitu Kementerian kelautan Perikanan. Gebrakan program yang dilakukan dalam upaya pengelolaan sumberdaya laut tersebut yaitu dengan mengeluarkan kebijakan moratorium kapal eks asing yang pembuatannya dilakukan di luar negeri dan transhipment. Kebijakan tersebut di keluarkan melalui Permen KP No.56/2014 dan No $57 / 2015$ tentang pelarangan praktek transhipment. Substansi dari aturan tersebut, yaitu melarang kapal eks asing dan transhipment untuk beroperasi di seluruh wilayah perairan Indonesia terhitung mulai tanggal 3 Nopember sampai 30 April 2015 langkah serius tersebut kemudian di lanjutkan dengan dikeluarkan Permen KP No Permen KP No.10/2015 tentang perpanjangan kebijakan moratorium yang menambah jangka waktu berhentinya operasi kapal eks asing sampai dengan Bulan Oktober 2015.

Berbagai bentuk kegiatan IUU fishing yang dilakukan pelaku, diantaranya adalah penjualan ikan di tengah laut dengan menggunakan kapal transhipment dan penangkapan menggunakan kapal eks asing berbendera Indonesia dengan izin yang digandakan. Bahkan modus operandi kegiatan IUU fishing ini terus berkembang sejalan dengan perkembangan teknologi komunikasi 
dan penangkapan. Namun demikian, upaya pemberantasannya pun tidak boleh surut agar mengurangi tindak kejahatan IUU Fishing.

Tulisan ini bertujuan untuk melihat efektivitas kebijakan untuk memberantas iUU Fishing terutama implementasi permen 56 dan 57 tahun 2014. Diharapkan dari hasil kajian ini dapat memberikan masukan kepada pengambil kebijakan serta pembaca lainnya faktor penentu keberhasilan pelaksnaan suatu program pemerintah serta dampaknya bagi masyarakat.

\section{METODOLOGI}

\section{Waktu dan Lokasi Penelitian}

Penelitian ini dilaksanakan pada bulan Maret sampai dengan April 2015, dengan dua lokasi penelitian yang dipilih secara purposive, yaitu Bitung dan DKI Jakarta. Bitung dipilih sebagai lokasi penelitian sebab lokasi tersebut memiliki tempat pendaratan ikan yang berskala besar, selain juga merupakan sentra usaha pengolahan produk KP dengan skala yang beragam - dari skala tradisional hingga ke skala yang modern. DKI Jakarta dipilih dengan alasan bahwa lokasi ini memiliki dua pelabuhan pendaratan ikan yang cukup besar dan merupakan sentra usaha pengolahan produk KP.

\section{Teknik Pengumpulan Data}

Jenis dari kajian ini pada dasarnya adalah sebuah studi kasus yang meneliti tentang status subyek penelitian yang berkenaan dengan suatu fase khas dari keseluruhan personalitas (Nazir, 1988). Subyek penelitian adalah para pelaku usaha di sektor KP sebagai pihak yang terkena langsung dampak dari kebijakan moratorium dan transshipment. Adapun data yang diambil meliputi baik data primer maupun data sekunder.

Data primer diperoleh dari analisis dokumen, observasi dan wawancara. Untuk memverifikasi data-data tersebut dilakukan proses triangulasi. Menurut Sitorus (1998), triangulasi dapat diartikan sebagai "kombinasi sumber data " yang memadukan sedikitnya tiga metode, seperti observasi, wawancara dan analisis dokumen. Kelebihan dari metode ini adalah saling menutupi kelemahan antara satu metode dengan metode lainnya sehingga hasil yang diharapkan dari realitas sosial masyarakat menjadi lebih valid. Observasi dilakukan untuk memperoleh gambaran lebih jelas tentang kehidupan sosial (Nasution, 2006).
Dengan observasi sebagai alat pengumpul data, diusahakan mengamati keadaan yang wajar dan yang sebenarnya tanpa usaha yang disengaja untuk mempengaruhi, mengatur atau memanipulasinya. Wawancara atau interview adalah suatu bentuk komunikasi verbal jadi semacam percakapan yang bertujuan untuk memperoleh informasi (Nasution, 2006).

Menurut Nasution (2006), Sumber data sekunder adalah sumber bahan bacaan. Bahan sekunder adalah hasil pengumpulan oleh orang lain dengan maksud tersendiri dan mempunyai kategorisasi atau klasifikasi menurut keperluan mereka. Data sekunder berupa bahan-bahan tertulis yang berupa laporan tahunan, hasil penelitian terdahulu (sebelumnya), buku serta publikasi media cetak maupun elektronik. Data ini dipakai sebagai pelengkap temuan atau sebagai starting point untuk memperoleh orientasi yang lebih luas mengenai topik yang diteliti. Sumber data sekunder yaitu: kementrian kelautan dan perikanan, pelabuhan perikanan, dinas kelautan dan perikanan, badan pusat statistik.

\section{Metoda Analisis Data}

Analisis data bertujuan untuk menyederhanakan data dalam bentuk yang lebih mudah dipahami (Nazir, 1988). Data yang telah terkumpul dalam penelitian ini dikelompokkan, kemudian disusun, ditabulasi dan dilakukan analisis secara deskriptif kualitatif. Analisis data dilakukan berdasarkan informasi yang didapat dari wawancara dan observasi lapang.

\section{EFEKTIVITAS KEBIJAKAN TERHADAP AKTIVITAS PENANGKAPAN IKAN}

Pemberlakuan kebijakan penghentian operasi penangkapan ikan oleh eks kapal asing dan trans-shipment diharapkan berdampak pada menurunnya praktek illegal fishing UnReported, UnRegulated (IUU) yang banyak dilakukan oleh kapal-kapal tersebut. Selain itu, tujuannya untuk menata ulang perizinan kapal penangkap ikan. Yang dimaksud dengan kapal eks asing yaitu Kapal perikanan Indonesia yang pembangunannya dilakukan di luar negeri (Anonim, 2015). Diduga banyak izin penangkapan yang disalahgunakan, duplikasi izin dan lain-lain. Selain itu, kapal-kapal trans-shipment diduga banyak melakukan transaksi ikan di tengah laut, sehingga ikan hasil tangkapannya tidak di daratkan di Indonesia. Menurut definisi, 
kapal asing adalah kapal yang dibuat negara asing, tapi beroperasi secara ilegal di perairan Indonesia, memiliki kapasitas di atas 30 GT yang telah mendapat Surat Izin Usaha Perikanan (SIUP) dan Surat Izin Usaha Penangkapan Ikan (SIPI) dari pemerintah. Praktek-praktek tersebut tentunya sangat merugikan bagi Indonesia. Dari data dapat dilihat jumlah pelanggaran yang dilakukan oleh kapal-kapal eks asing dan kapal trans-shipment selama kurun waktu 5 tahun terakhir (Tabel 1).

Laporan dari Tim Satgas Pemberantasan di Maluku, praktik manipulasi data dengan menurunkan ukuran kapal di dokumen (mark down), berlayar tanpa Surat Laik Operasi (SLO), dan lainnya, pemalsuan dokumen dan isi kapal. Kapal-kapal itu ukurannya antara 100-300 Gross Ton (GT), tapi, dilaporkan di bawah 50 GT.

Semenjak Permen KP No. 56/2014 dan Permen KP No. 57/2014 diberlakukan pada awal november 2014 hingga April 2015 ini, tercatat telah terjadi penurunan kapal yang melaut di Pelabuhan

Tabel 1. Hasil Operasi Kapal Pengawas Tahun 2010-2013.

Table 1. The Results of Patrol Vessels, 2010-2013.

\begin{tabular}{ccccc}
\hline Tahun & $\begin{array}{c}\text { Diperiksa/ } \\
\text { Checked }\end{array}$ & \multicolumn{3}{c}{$\begin{array}{c}\text { Ditangkap/ } \\
\text { Apprehended }\end{array}$} \\
\cline { 2 - 5 } & $\begin{array}{c}\text { Unit Kapal/ } \\
\text { Vessels }\end{array}$ & KII & KIA & KII+KIA \\
\hline 2010 & 2,253 & 24 & 159 & 183 \\
2012 & 3,348 & 31 & 75 & 106 \\
2013 & 4,326 & 42 & 70 & 112 \\
2014 & 3,871 & 24 & 44 & 68 \\
\hline
\end{tabular}

Sumber: PSDKP-KKP/ Source: PSDKP-KKP

Keterangan/ Description: KII = Kapal Ikan Indonesia/

Indonesian Fishing Ships; KIA= Kapal Ikan Asing/ Foreign Fishing Ships

Illegal Unreported dan Unregulated (IUU) Fishing Kementerian Kelautan dan Perikanan (KKP) menyatakan bahwa dari 1.132 kapal eks asing sebanyak 907 telah ditemukan melanggar. Jenis pelanggaran di antaranya tidak mengaktifkan Vessel Monitoring System (VMS) saat berlayar. Kalau mematikan alat itu sehingga tidak bisa dimonitor, mematikan alat itu mencapai berbulanbulan, semua anak buah kapal (ABK) adalah warga asing, mempraktikan perbudakan sebagaimana
Perikanan Samudera (PPS) Nizam Zachman seperti yang ditampilkan pada Tabel 2. Dari Tabel tersebut dapat kita lihat bahwa secara total, semenjak kedua peraturan diberlakukan, telah terjadi penurunan jumlah kapal yang melaut dariPPS Nizam Zachman sebesar rata-rata 5\% per bulan, atau secara total sebesar 24\%. Apabila dikelompokkan berdasarkan jenis kapal/alat tangkapnya, maka penurunan melaut tertinggi terjadi pada kapal jenis angkut, kelompok berikut

Tabel 2. Data Keberangkatan Kapal dari PPS Nizam Zachman Berdasarkan Jenis Kapal, Oktober 2014-Februari 2015.

Table 2. Vessel Departures From PPS Nizam Zachman According to Gear Classification, October 2014 - February 2015.

\begin{tabular}{lrrrrr}
\hline \multicolumn{1}{c}{ Jenis Kapal } & Oktober & November & Desember & Januari & Februari \\
\hline Angkut & 70 & 78 & 37 & 34 & 24 \\
Bouke Ami & 158 & 165 & 122 & 87 & 167 \\
Lain-lain & 9 & 12 & 12 & 122 & 5 \\
Pukat Cincin & 118 & 108 & 80 & 0 & 82 \\
Rawai Tuna & 45 & 40 & 24 & 5 & 26 \\
Total & $\mathbf{4 0 0}$ & $\mathbf{4 0 3}$ & $\mathbf{2 7 5}$ & $\mathbf{2 4 8}$ & $\mathbf{3 0 4}$ \\
\hline
\end{tabular}

Sumber: PPS NIZAM ZACHMAN Jakarta, 2015/ Source: PPS NIZAM ZACHMAN, Jakarta, 2015 
yang mengalami penurunan tertinggi, dengan total sebesar $44 \%$, dan Rawai Tuna, dengan total sebesar $42 \%$.

Nampaknya pemberlakuan kedua peraturan yang berbarengan dengan terjadinya musim pacekliklah yang telah mengakibatkan terjadinya penurunan tersebut. Hal tersebut dapat dilihat dari terjadinya fenomena penurunan yang diikuti dengan peningkatan. Tabel 2 menunjukkan bahwa penurunan terjadi sejak bulan November 2014 dan mengalami titik paling rendah pada bulan Januari 2015, dengan angka penurunan sebesar $38 \%$ dari angka bulan Oktober 2014. Akan tetapi bersamaan dengan mulai berakhirnya musim paceklik, pada bulan Februari 2015 mulai terjadi peningkatan jumlah kapal yang melaut, meskipun dengan angka yang masih di bawah angka bulan Oktober 2014. Walaupun terjadi peningkatan akan tetapi telah terjadi penurunan kapal yang melaut dengan rata-rata sebanyak $20 \%$ per bulan, atau secara total, sebanyak $66 \%$ sepanjang periode pengamatan.

Dari sisi produksi, secara total, terjadi kecenderungan penurunan total produksi tangkapan yang didaratkan di PPS Nizam Zachman dengan rata-rata $11 \%$ perbulannya sepanjang periode Oktober 2014 hingga Februari 2015 ini. Serupa dengan angka kapal yang melaut, kecenderungan tersebut nampaknya terjadi sebagai akibat dari pengaruh musim penangkapan saja. Hal tersebut dapat dilihat dari penurunan yang mencapai titik terendah di angka 5780 Ton pada bulan Januari 2015, dan meskipun belum menyamai angka produksi pada Oktober 2014, akan tetapinampaknya mulai terjadi kecenderungan peningkatan produksi tangkapan pada bulan Februari 2015, seiring dengan mulai bergantinya musim tangkapan (Tabel 3).

Apabila data tersebut dipilah berdasarkan alat tangkap yang digunakan, dapat dilihat bahwa Kedua PERMEN KP, yang diberlakukan pada November 2015 lalu, nampaknya sangat berdampak terhadap kegiatan operasi Kapal Angkut - yang umumnya melakukan kegiatan Trans-shipment. Meskipun pada awal diberlakukan PERMEN terkait trans-shipment memang sempat terjadi puncak pendaratan ikan bagi Kapal Angkut pada angka 2321 Ton, akan tetapi selepas itu terjadi penurunan pendaratan yang luarbiasa signifikan dan terjadi penghentian secara total operasi pengangkutan pada bulan Januari dan Februari 2015 ini.

Pada Tabel 4, terlihat jumlah kapal yang berlayar sejak diberlakukannya peraturan menteri kelautan terkait moratorium. Secara umum, terjadi pertumbuhan yang negatif $-0,141$ yang menunjukkan terjadi penurunan jumlah kapal yang berlayar.

\section{EFEKTIVITAS TERHADAP KINERJA USAHA PENANGKAPAN}

\section{Kinerja Usaha Penangkapan Skala Besar}

Gambaran tentang dampak kebijakan terhadap usaha penangkapan ikan skala besar diambil contoh lokasi di Pelabuhan Nizam Zachman (DKI Jakarta). Dari hasil penelitian menunjukkan bahwa telah terjadi perubahan besar sebagai dampak langsung dari adanya pemberlakuan

Tabel 3. Data Produk Tangkapan yang Didaratkan di PPS Nizam Zachman Berdasarkan Jenis Kapal, Oktober 2014-Februari 2015.

Table 3. Landed Catch at PPS Nizam Zachman According to Gear Classification, October 2014 February 2015.

\begin{tabular}{|c|c|c|c|c|c|}
\hline \multirow[b]{2}{*}{ Jenis Kapal/ Boat } & \multicolumn{5}{|c|}{ Produksi/ Production (Satuan: Ton) } \\
\hline & $\begin{array}{c}\text { Oktober } \\
2014\end{array}$ & $\begin{array}{l}\text { November } \\
2014\end{array}$ & $\begin{array}{c}\text { Desember } \\
2014\end{array}$ & $\begin{array}{c}\text { Januari } \\
2015\end{array}$ & $\begin{array}{c}\text { Februari } \\
2015\end{array}$ \\
\hline Angkut/ Transports & $1,867,535$ & $2,321,399$ & 979,001 & 0 & 0 \\
\hline Bouke Ami & $1,840,515$ & $1,148,508$ & $1,650,231$ & $1,460,654$ & 722,113 \\
\hline Pukat Cincin/ Purse seine & $6,526,409$ & $4,769,734$ & $5,491,662$ & $3,777,331$ & $5,292,066$ \\
\hline $\begin{array}{l}\text { Rawai Tuna/ Tuna } \\
\text { Longline }\end{array}$ & $1,079,691$ & 734,138 & 360,481 & 379,65 & 444,092 \\
\hline Lainnya/ Others & 3.76 & 0 & 314,007 & 162,734 & 7,676 \\
\hline Jumlah/Total & $11,317.91$ & $8,973,779$ & $8,795,382$ & $5,780,369$ & 6465,947 \\
\hline
\end{tabular}

Sumber: Olahan Data PPS Nizam Zachman, 2015/ Source: PPS Nizam Zachman, 2015 
Tabel 4. Jumlah Persetujuan Berlayar (SPB) Berdasarkan Jenis Kapal, Oktober 2014 - Februari 2015 di PPS Bitung.

Table 4. Approved Departures According to Gear Classification, October 2014 - February 2015.

\begin{tabular}{|c|c|c|c|c|c|c|}
\hline $\begin{array}{c}\text { Alat tangkap/ } \\
\text { Gear }\end{array}$ & $\begin{array}{l}\text { Oktoberl } \\
\text { October }\end{array}$ & $\begin{array}{l}\text { Nopemberl } \\
\text { November }\end{array}$ & $\begin{array}{l}\text { Desemberl } \\
\text { December }\end{array}$ & $\begin{array}{l}\text { Januari/ } \\
\text { January }\end{array}$ & $\begin{array}{l}\text { Februari/ } \\
\text { February }\end{array}$ & $\begin{array}{l}\text { Pertumbuhan/ } \\
\text { Growth }\end{array}$ \\
\hline Bottom Long Line & 0 & 1 & 0 & 0 & 0 & - \\
\hline Gill Net & 5 & 2 & 0 & 0 & 0 & - \\
\hline Hand line & 82 & 71 & 46 & 40 & 41 & -0.13863 \\
\hline $\begin{array}{l}\text { Kapal Latih/ } \\
\text { Training ship }\end{array}$ & 1 & 1 & 2 & 0 & 0 & - \\
\hline $\begin{array}{l}\text { Kapal Penelitian/ } \\
\text { Research ships }\end{array}$ & 0 & 1 & 1 & 0 & 0 & - \\
\hline Light Boat & 44 & 36 & 36 & 57 & 34 & -0.05157 \\
\hline $\begin{array}{l}\text { Pancing Cumi/ } \\
\text { Squid fishing }\end{array}$ & 0 & 0 & 0 & 0 & 0 & - \\
\hline $\begin{array}{l}\text { Pengangkut/ } \\
\text { Transporter }\end{array}$ & 214 & 187 & 78 & 40 & 36 & -0.35649 \\
\hline Pole and Line & 78 & 71 & 31 & 36 & 28 & -0.2049 \\
\hline $\begin{array}{l}\text { Pukat ikan/ Trawl } \\
\text { fishing }\end{array}$ & 0 & 3 & 0 & 0 & 0 & - \\
\hline Purse Seine & 274 & 242 & 258 & 252 & 236 & -0.02986 \\
\hline Tuna Hand line & 532 & 579 & 315 & 371 & 234 & -0.16426 \\
\hline Tuna long line & 11 & 15 & 6 & 4 & 2 & -0.34095 \\
\hline $\begin{array}{l}\text { Kapal Izin baru/ } \\
\text { New permit ships }\end{array}$ & 0 & 0 & 0 & 4 & 0 & - \\
\hline Jumlah/Total & 1,241 & 1,209 & 773 & 804 & 611 & -0.14172 \\
\hline
\end{tabular}

Sumber: PPS Bitung 2014 - 2015/ Source: PPS Bitung 2014 - 2015

kebijakan tersebut. Bagi usaha penangkapan skala besar, pemberlakuan berdampak pada menurunnya kinerja usaha penngkapan ikan skala besar. Penghentian operasi kapal-kapal eks asing dan trans-shipment mengurangi kapasitas usaha penangkapan yang dilakukan lebih dari $50 \%$. Menurut responden pemberlakuan kebijakan diterapkan untuk semua kapal eks asing dan trans-shipment baik untuk yang melanggar maupun bagi yang taat peraturan. Akibatnya, bagi pemilik kapal yang tidak melanggar aturan pun mendapat dampaknya karena tidak dapat beroperasinya kapal-kapal yang dimiliki. Strategi yang dilakukan oleh pengusaha dalam menghadapi situasi tersebut dengan memberhentikan Anak Buah Kapal (ABK) kapal eks asing dan tetap menggaji Nakhodanya.

Berdasarkan pengamatan di lapangan, nampaknya kedua peraturan tersebut sangat efektif dan tepat sasaran dalam memenuhi tujuannya. Kebijakan moratorium telah berhasil menghentikan kegiatan penangkapan ikan oleh kapal eks asing, yang dapat dilihat dari menghilangnya kapal-kapal eks asing yang biasanya beroperasi di Pelabuhan Perikanan Samudera Bitung dan Nizam Zahman (DKI Jakarta). Kebijakan penghentian praktek trans-shipment juga telah diberlakukan dengan efektif, yang ditunjukkan dengan banyaknya kapal pengangkut yang bersandar di Pelabuhan Nizam Zahman.

Dari fakta tersebut, maka dapat disimpulkan bahwa pelaku usaha yang terkena dampak secara langsung dari kedua kebijakan tersebut adalah para pemilik kapal eks asing dan kapal pengangkut yang biasa melakukan trans-shipment. Dampak yang diterima tersebut muncul dalam bentuk berkurangnya kegiatan operasional penangkapan dan pengangkutan, serta meningkatnya biaya operasional penangkapan. Selain para pemilik kapal, dampak langsung juga dirasakan oleh para ABK termasuk Nakhoda melalui hilangnya sumber pendapatan dan/ atau turunnya pendapatan akibat berkurangnya waktu melaut 
Usaha penunjang bagi penangkapan mengalami kelesuan usaha. Usaha penunjang seperti Penyedia Ransum, Perbaikan Kapal dan Alat-alat Perikanan adalah beberapa dari usaha penunjang yang mengalami kelesuan usaha akibat penurunan permintaan. Di sisi lain, usaha jasa transportasi darat dan jasa penyewaan cold storage di beberapa pelabuhan ternyata menerima dampak positif dari kedua kebijakan tersebut. Hal tersebut berkaitan dengan dilarangnya praktek transhipment, yang menyebabkan banyak usaha penangkapan di Jakarta memutuskan untuk melakukan penyewaan cold storage di pelabuhan terdekat dari fishing ground, yaitu Cilacap dan Pelabuhanratu, untuk ditimbun hingga jumlahnya mencukupi untuk diangkut menggunakan kapal angkut secara port to port. Selain itu, banyak usaha penangkap ikan bernilai ekonomis tinggi, semisal tuna, memilih untuk mendaratkan tangkapannya di pelabuhan terdekat fishing ground dan langsung mengirimkannya ke UPI di Jakarta melalui alat transportasi darat.

Dari hasil wawancara dengan pelaku usaha diperoleh informasi dampak kebijakan yang dirasakan sangat berpengaruh terhadap kinerja usahanya. Dari produksi ikan yang dihasilkan terjadi penurunan karena tidak beroperasinya kapal-kapal eks asing yang dimiliki serta kapal transhipment. Kapal ikan yang dioperasikan hanya kapal-kapal purse seine yang beroperasi di Laut Jawa saja. Kapal-kapal tersebut tidak memiliki palka yang banyak, sehingga penangkapan ikan dilakukan hanya memenuhi volume palka yang ada. Penurunan produksi tersebut tercermin dari menurunnya jumlah ikan yang didaratkan di pelabuhan Nizam Zahman sebelum dan sesudah kebijakan mencapai $11 \%$.

Dampak lainnya, terjadi pengurangan jumlah hari melaut dalam sebulan dari 3-5 bulan per trip menjadi 2 bulan per trip. Hal ini disebabkan pasokan BBM yang semula di bawa oleh kapal transhipment sudah tidak dapat dipasok lagi. Penangkapan dilakukan berdasarkan ketersediaan BBM yang dibawa. Akibatnya pendapatan nelayan terutama nelayan $A B K$ menurun karena kehilangan pendapatan yang berasal dari bonus tangkapan ikan jenis lainnya.

Secara lebih rinci dampak kebijakan terhadap kinerja usaha penangkapan skala besar dapat dilihat pada Tabel 5.
Disamping dampak langsung terhadap pelaku usaha penangkapan, implementasi kebijakan moratorium telah berdampak pada sektor usaha pendukung lainnya. Seperti diketahui, sektor pendukung usaha perikanan terdiri dari usaha warung makan, jasa angkut, usaha transportasi, toko alat perikanan, penyedia perbekalan melaut, perbengkelan.

Terjadi kelesuan konsumen bagi warungwarung makan yang ada di sekitar Pelabuhan Nizam Zahman setelah diberlakukannya kebijakan moratorium. Dampak yang ditimbulkan menurunnya omzet usaha dari warung kakan yang ada mencapai $50 \%$.

Usaha jasa terdiri dari jasa bongkar muat (ikan, perbekalan), jasa transportasi juga ikut terkena dampak karena aktivitas bongkar muat ikan menurun setelah berhentinya kapal-kapal eks asing dan transhipment.

Usaha pendukung seperti bengkel/docking, rumah makan, jasa angkut, toko penyedia alat perikanan, perbekalan melaut bagi penangkapan ikan juga terkena dampak langsung karena menurunnya operasi kapal ikan. Penurunan omzet mencapai $>50 \%$. Selain itu usaha perbengkelan yang juga terkena dampak tidak langsung dari adanya kebijakan moratorium

\section{Kinerja Usaha Penangkapan Skala Kecil}

Lokasi penelitian yang di tujukan untuk melihat dampak kebijakan moratorium dan transhipment terhadap kinerja usaha skala kecil dilakukan Pelabuhan Bitung. Berbeda dengan usaha penangkapan skala besar, usaha penangkapan skala kecil mendapat manfaat dari pemberlakuan kebijakan tersebut. Dari hasil penelitian menunjukkan terjadi peningkatan aktivitas kapal ikan 10 GT yang melakukan kegiatan penangkapan pasca pemberlakuan kebijakan.

Dampak kebijakan terhadap kinerja usaha perikanan skala kecil di Bitung dapat digambarkan sebagai berikut:

Pertama, terjadi peningkatan produksi hasil tangkapan ikan oleh perahu ukuran $10 \mathrm{GT}$ hingga $200 \%$ yaitu terjadi peningkatan produksi yang dihasilkan oleh nelayan 10 GT mencapai $200 \%$. Peningkatan produksi tersebut menyebakan meningkatnya pendapatan nelayan $>80 \%$. 
Tabel 5. Kinerja Usaha Perikanan Tangkap Sebelum dan Sesudah Implementasi Kebijakan Di DKI Jakarta Tahun 2015.

Table 5. Captured Fisheries Performance, Before and After Policy Implementation, DKI Jakarta 2015.

\begin{tabular}{ccc}
\hline & \multicolumn{2}{c}{ Jakarta } \\
\cline { 2 - 3 } Uraian/ & Sebelum Permen 56/2014 I & Setelah Permen 56/2014 I \\
Pre-Permen 56/2014 & Post-Permen 56/2014
\end{tabular}

$\begin{array}{ll}\text { Produksi/ Production } & \text { Produksi yang tercatat di PPS Nizam } \\ & \text { Zahman pada Bulan Nopember } 2014 \\ & \text { sebanyak 8.973,779 ton / Production } \\ & \text { recorded at PPS Nizam Zachman in } \\ & \text { November } 2014 \text { was } 8.973,779\end{array}$

Jumlah Trip/ Number of Trips

Pendapatan nelayan/ Revenue

Jarak Fishing

Ground/ Distance to

Fishing Ground

Harga Ikan/ Price

Penggunaan BBM/ Petrol usage

Jumlah kapal yang melaut/ Operating vessels
- Jumlah trip kapal transhipment 6 12 bulan/trip/ The length of trip taken by transhipment vessels were 6-12 month

- Jumlah hari melaut Kapal < 30 GT 3-5 bln (BBM di supply)/ The number of days at sea of $<30$ GT vessels were 3-5 months

- > 30 GT kapasitas palka 50 ton namun hasil tangkapan dapat mencapai 100 ton/trip/ A 50 GT Vessel may catch up to 100 Tonnes/ Trip

Pendapatan nelayan < 30 GT

Rp. 15000/hari di tambah bonus/

The average revenue of $<30 \mathrm{GT}$ fishers was Rp. 15.000/ day

Kapal-kapal transhipmen > 30 GT Laut Jawa dan Samudera Hindia/ Around the Java Sea and the Indian Ocean for > 30 GT transhipment vessels

Rata-rata harga ikan hasil tangkapan kapal < 30 GT Rp. 10000/kg/ The average Price of < 30 GT vessels' Catch was Rp. 10.000/kg

penggunaan BBM mengandalkan dari tambahan supply dapat mencapai 750 kiloliter/ Petrol usage pertrip may used up to 750 Kilolitre

Kapal kapal transhipment seluruhnya dapat beroperasi/ The transhipment vessels were fully operating
- Terjadi penurunan produksi ikan yang didaratkan sebesar $11 \%$ per bulan/ Monthly average of $11 \%$ reduction in fish landed

- Terjadi peningkatan produksi walaupun tidak signifikan oleh kapal <30 GT/ Subtle raise in production of $<30 \mathrm{GT}$ vessels

- Jumlah trip kapal transhipmen menjadi 2-4 bulan/trip/ The length of trip taken by transhipment vessels were 2-4 months

- Jumlah hari melaut Kapal < 30 GT berkurang menjadi 2 bln sesuai BBM/ The number of days at sea of $<30 \mathrm{GT}$ vessels were 2 months

- Produksi tangkapan sesuai dengan kapasitas palka nya/ Production has been as large as the capacity

Penururnan pendapatan nelayan $<30$ GT berkurang karena tidak mendapatkan bonus/ Decreasing revenue of $<30$ GT fishers due to less bonus received

Tetap di wilayah Laut Jawa/ Around the Java Sea

Rata-rata harga ikan meningkat menjadi Rp. 12.000/kg/ The average price has been rising to $R p$. $12000 / \mathrm{Kg}$

Penurunan konsumsi BBM menjadi 250 kiloliter karena hanya untuk penggunaaan satu trip saja/ petrol usage pertrip has been down to only 250 kilolitre

Mengalami penurunan kapal yang beroperasi rata-rata $11 \%$ / The average transhipment vessels operation has been decreasing by $11 \%$

Usaha pendukung/ - Mengalami kelesuan usaha akibat berkurangnya permintaan atas jasa yang Supportive business disediakan/ Has been waning as the demand for their services had been decreasing

Sumber: Data Diolah/ Source: Data Processed 
Pendapatan nelayan juga didukung oleh adanya kenaikan harga ikan hasil tangkapan nelayan dari Rp. 5.000/ kg menjadi rata-rata Rp. $10.000 / \mathrm{kg}$.

Kedua, telah terjadi penurunan biaya operasional penangkapan hingga mencapai $30 \%$. Hal ini disebabkan jarak fishing gound berkurang. Wilayah penangkapan ikan untuk perahu ukuran 10 GT awalnya mencapi 4 mil setelah implementasi kebijakan hanya 2 mil saja. Hal ini diduga banyaknya ikan yang berenang di perairan lebih dekat disebabkan berkurangnya aktivitas penangkapan oleh kapal-kapal eks asing dan transhipment. Secara lebih rinci, dampak kebijakan terhadap kinerja usaha skala kecil dapat dilihat pada Tabel 6.

\section{EFEKTIVITAS TERHADAP PENINGKATAN KINERJA USAHA PENGOLAHAN}

Kebijakan moratorium telah nyata berdampak pada usaha pengolahan baik pengolahan skala besar maupun skala kecil. Hal ini diketahui dari adanya pengaruh yang berdampak negatif yang disebabkan kebijakan tersebut.

Tabel 6. Kinerja Usaha Perikanan Tangkap Sebelum dan Sesudah Implementasi Kebijakan Moratorium Di Bitung (Sulawesi Utara) Tahun 2015.

Table 6. Captured Fisheries Performance Before and After Policy Moratorium Implementation, Bitung (North Sulawesi) - 2015.

\begin{tabular}{|c|c|c|}
\hline \multirow{2}{*}{$\begin{array}{l}\text { Uraian/ } \\
\text { Descripton }\end{array}$} & \multicolumn{2}{|c|}{ Bitung } \\
\hline & $\begin{array}{c}\text { Sebelum Permen 56/2014 I } \\
\text { Pre-Permen 56/2014 }\end{array}$ & $\begin{array}{l}\text { Setelah Permen 56/2014/ } \\
\text { Post-Permen 56/2014 }\end{array}$ \\
\hline Produksi/ Production & $\begin{array}{l}\text { - Produksi kapal (10GT) } 100-500 \mathrm{~kg} / \\
\text { trip/ } 10 \mathrm{GT} \text { vessels were producing } \\
\text { at an average of } 100-500 \mathrm{Kg} / \text { trip }\end{array}$ & $\begin{array}{l}\text { - Produksi kapal (10 GT) meningkat } \\
200 \% / \text { the average production of } 10 \\
\text { GT vessels may rise up to } 200 \%\end{array}$ \\
\hline $\begin{array}{l}\text { Jumlah trip/ Number } \\
\text { of Trips }\end{array}$ & $\begin{array}{l}\text { Jumlah trip kapal < } 10 \text { GT sebanyak } \\
2-3 \text { hari/trip/ the average legth of trip } \\
\text { taken by less than } 10 \text { GT vessels was } \\
2-3 \text { days/trip }\end{array}$ & $\begin{array}{l}\text { Jumlah trip kapal < } 10 \text { GT meningkat } \\
\text { menjadi } 1 \text { hari /trip/ the length of trip } \\
\text { has been down to } 1 \text { day/trip }\end{array}$ \\
\hline $\begin{array}{l}\text { Pendapatan } \\
\text { nelayan/ Revenue }\end{array}$ & $\begin{array}{l}\text { - Nelayan dengan kapal < } 10 \mathrm{GT} \\
\text { memperoleh pendapatan hanya Rp } \\
50.000-150.000 \text { /hari/ the average } \\
\text { revenue of }<10 \mathrm{GT} \text { fishers was Rp. } \\
50.000-150.000 / \text { day }\end{array}$ & $\begin{array}{l}\text { - Pendapatan nelayan tradisional } \\
\text { meningkat }>80 \% / \text { the average } \\
\text { revenue has been rising as much as } \\
80 \%\end{array}$ \\
\hline $\begin{array}{l}\text { Jarak Fishing } \\
\text { Ground/ Distance to } \\
\text { Fishing Ground }\end{array}$ & $\begin{array}{l}\text { Wilayah penangkapan kapal < } 10 \mathrm{GT} \\
\text { di lokasi } 4 \mathrm{mil} / 4 \text { miles }\end{array}$ & $\begin{array}{l}\text { Wilayah tangkapan berkurang di } \\
\text { sekitar } 2 \text { mil karena sudah banyak } \\
\text { ikan/ has been reduced to only } 2 \text { miles }\end{array}$ \\
\hline Harga Ikan/ Price & $\begin{array}{l}\text { Harga ikan hasil tangkapan nelayan } \\
<10 \mathrm{GT} \text { : Rp. } 5.000 / \mathrm{kg} / \text { Price of } \\
\text { captured fish Rp. } 5.000 / \mathrm{Kg}\end{array}$ & $\begin{array}{l}\text { - Terjadi peningkatan harga ikan } \\
\text { menjadi } 10.000 \mathrm{rb} / \mathrm{kg}(100 \%) / \mathrm{Price} \\
\text { has been rising to Rp. } 10.000 / \mathrm{Kg}\end{array}$ \\
\hline \multirow[t]{2}{*}{$\begin{array}{l}\text { Penggunaan BBM/ } \\
\text { Petrol Usage }\end{array}$} & $\begin{array}{l}\text { - Akses BBM utk nelayan perahu < } \\
10 \mathrm{GT} \text { sulit/ it was difficult for the < } \\
10 \mathrm{GT} \text { vessels to get Petrol }\end{array}$ & \multirow{2}{*}{$\begin{array}{l}\text { - Akses memperoleh BBM lebih } \\
\text { mudah/ has been easier to get petrol } \\
\text { - kapal < } 10 \mathrm{GT} \text { konsumsi BBM } \\
\text { berkurang } 30 \% / \text { petrol consumption } \\
\text { has been reduced by } 30 \%\end{array}$} \\
\hline & $\begin{array}{l}\text { - Kapal tuna < } 10 \mathrm{GT} 350 \text { liter/ the } \\
\text { average petrol usage for }<10 \mathrm{GT} \\
\text { Vessels was } 350 \text { litre pertrip }\end{array}$ & \\
\hline $\begin{array}{l}\text { Jumlah kapal yang } \\
\text { melaut/ Operating } \\
\text { Vessels }\end{array}$ & $\begin{array}{l}\text { - Kapal < } 10 \mathrm{GT} \text { yang beroperasi } \\
\text { terbatas/ limited number of }<10 \mathrm{GT} \\
\text { vessels }\end{array}$ & $\begin{array}{l}\text { - Jumlah operasi kapal < } 10 \mathrm{GT} \\
\text { meningkat/ more vessels have been } \\
\text { operating }\end{array}$ \\
\hline
\end{tabular}

Sumber: Data Diolah/ Source: Data Processed 
Kebijakan moratorium di kedua lokasi penelitian secara umum menunjukkan kurang efektif untuk peningkatan kinerja usaha pengolahan khususnya usaha pengolahan skala besar. Dari hasil penelitian, menunjukkan beberapa gambaran dampaknya seperti terlihat pada Tabel 7 .

Kebijakan telah berdampak pada penurunan produksi hasil olahan dan waktu beroperasinya unit pengolahan ikan. Pengurangan produksi mencapai lebih dari 50\%. Disamping itu, jumlah UPI yang masih beroperasi berkurang cukup besar. Akibatnya, terjadi PHK tenaga kerja di UPI dan pengurangan jam kerja atau penggiliran waktu bekerja. Biaya perolehan bahan baku meningkat lebih dari $50 \%$. Hal ini disebabkan berubahnya lokasi pasokan bahan baku seperti yang terjadi di Bitung. Bahan baku dipasok dari Gorontalo, karena dari pelabuhan Bitung tidak dapat memasok ikan lagi.

Penurunan produksi yang disebabkan sulitnya pasokan bahan baku telah menyebabkan terganggunya ekspor ikan oleh UPI yang sudah di sepakati sebelumnya. Kekhawatiran para pelaku usaha pengolahan mendapat "complain" dari negara importir.

Tabel 7. Kinerja Usaha Pengolahan Ikan Sebelum dan Sesudah Implementasi Kebijakan Moratorium di Bitung (Sulawesi Utara) Tahun 2015.

Table 7. Fish Processing Performance Before and After Policy Moratorium Implementation, Bitung (North Sulawesi) - 2015.

\begin{tabular}{|c|c|c|}
\hline \multirow{2}{*}{$\begin{array}{l}\text { Uraian/ } \\
\text { Description }\end{array}$} & \multicolumn{2}{|r|}{ Bitung } \\
\hline & Sebelum/Before & Sesudah After \\
\hline Produksi / Production & $\begin{array}{l}\text { - Waktu produksi } 7 \text { hari kerja/ } \\
\text { minggu / Producing } 7 \text { days a week } \\
\text { - Pasokan ikan stabil / Stable fish } \\
\text { supply }\end{array}$ & $\begin{array}{l}\text { - Waktu produksi 2-3 hari kerja/minggu / } \\
\text { Production has been down to only 2-3 days } \\
\text { a week } \\
\text { - Berkurang > } 50 \% \text {, karena kekurangan } \\
\text { bahan baku / Has been down by more than } \\
50 \% \text { due to the lack of fish fupply }\end{array}$ \\
\hline $\begin{array}{l}\text { Jumlah UPI yang masih } \\
\text { beroperasi/ Number of } \\
\text { Operating UPI }\end{array}$ & $\begin{array}{l}\text { Jumlah UPI di dalam pelabuhan } 8 \\
\text { unit / } 8 \text { units of UPI within the port }\end{array}$ & $\begin{array}{l}\text { Jumlah UPI di dalam pelabuhan yang } \\
\text { beroperasi } 6 \text { unit / Only } 6 \text { UPI left operating } \\
\text { within the port }\end{array}$ \\
\hline Tenaga Kerja / Labor & $\begin{array}{l}\text { - } 700.000 \text { per minggu / the average } \\
\text { income was Rp. } 700.000 / \text { week } \\
\text { - jumlah jam kerja } 60-70 \text { jam per } \\
\text { minggu / working hour was about } \\
60-70 \text { hours a week }\end{array}$ & $\begin{array}{l}\text { - Terjadi pengurangan tenaga kerja } \\
\text { sebanyak } 80 \% \text { / Labor has been reduced } \\
\text { by } 80 \% \\
\text { - Dilakukan sistem rolling pegawai / Rolling } \\
\text { system has been applied } \\
\text { - Jumlah jam kerja } 12 \text { - } 24 \text { jam per minggu/ } \\
\text { Working hour has been down to 12-24 } \\
\text { hours a week }\end{array}$ \\
\hline $\begin{array}{l}\text { Supply lkan ke Pasar } \\
\text { Ekspor / Export supply }\end{array}$ & Normal / Normal & $\begin{array}{l}\text { Supply ikan kalengan berkurang } 70 \% \text { / } \\
\text { Canned fish supply has been down by } 70 \%\end{array}$ \\
\hline $\begin{array}{l}\text { Pasokan Bahan baku / } \\
\text { Raw material supply }\end{array}$ & $\begin{array}{l}\text { Sumber pasokan dari dalam Bitung / } \\
\text { supplied by bitung producers }\end{array}$ & $\begin{array}{l}\text { - Berkurang hanya mengandalkan pasokan } \\
\text { dari kapal-kapal kecil. / Lower supply from } \\
\text { only small vessels } \\
\text { - UPI Cakalang fufu (asap), pasokan bahan } \\
\text { baku mendatangkan dari luar propinsi } \\
\text { (Gorontalo) pasokan bahan baku cakalang } \\
\text { berkurang sebanyak 50\% / UPI have been } \\
\text { getting fish supply from Gorontalo }\end{array}$ \\
\hline
\end{tabular}

Biaya perolehan bahan baku / Cost of inputs
Mengalami peningkatan $>50 \%$ karena harus mendatangkan dari Gorontalo /

Cost of input has been rising by more than $50 \%$ 
Tabel 8. Kinerja Usaha Pengolahan Ikan Sebelum dan Sesudah Implementasi Kebijakan Moratorium Di DKI Jakarta Tahun 2015.

Table 8. Fish Processing Performance Before and After Policy Moratorium Implementation, DKI Jakarta, 2015.

\begin{tabular}{|c|c|c|}
\hline \multirow{2}{*}{$\begin{array}{l}\text { Uraian/ } \\
\text { Description }\end{array}$} & \multicolumn{2}{|c|}{ Jakarta } \\
\hline & Sebelum / Before & Sesudah / After \\
\hline \multirow[t]{2}{*}{ Produksi / Production } & $\begin{array}{l}\text { Waktu produksi } 7 \text { hari per minggu } \\
\text { karena supply bahan baku lancar / } 7 \\
\text { days a week }\end{array}$ & $\begin{array}{l}\text { - Produksi berkurang } 50 \% \text {, karena } \\
\text { pasokan bahan baku tersendat / } \\
\text { Unstable input supply, production has } \\
\text { been down by } 50 \%\end{array}$ \\
\hline & & $\begin{array}{l}\text { - Bahan Baku impor dari Jepang/ Has } \\
\text { been importing fish from Japan for } \\
\text { input }\end{array}$ \\
\hline $\begin{array}{l}\text { Jumlah UPI yang masih } \\
\text { beroperasi / Number of } \\
\text { Operating UPI }\end{array}$ & $\begin{array}{l}\text { UPI tuna masih } 50 \% \text { operasi / } \\
\text { as many as } 50 \% \text { of UPls were } \\
\text { operating }\end{array}$ & $\begin{array}{l}\text { - UPI Tuna berkurang tinggal sekitar } \\
30 \% \text { / Tuna UPIs have been down to } \\
\text { only } 30 \% \text { left }\end{array}$ \\
\hline Tenaga Kerja / Labor & $\begin{array}{l}\text { Hari Kerja } 7 \text { hari oper minggu / } \\
\text { worked } 7 \text { days a week }\end{array}$ & $\begin{array}{l}\text { Jumlah hari kerja berkurang } 50 \% \text { / } \\
\text { Working days have been down by } 50 \%\end{array}$ \\
\hline $\begin{array}{l}\text { Supply Ikan Ke Pasar Ekspor/ } \\
\text { Export supply }\end{array}$ & Normal / Normal & $\begin{array}{l}\text { Berkurang } 75 \% \text { perbulan / Export has } \\
\text { been dwindling by } 75 \% \text { permonth }\end{array}$ \\
\hline $\begin{array}{l}\text { Pasokan Bahan baku / Raw } \\
\text { Material Supply }\end{array}$ & $\begin{array}{l}\text { Dari kapal-kapal transhipment } \\
\text { sendiri atau sekitar Muara Baru/ } \\
\text { Supplied by own transhipment } \\
\text { vessels or other suppliers around } \\
\text { Muara Baru }\end{array}$ & $\begin{array}{l}\text { Mengandalkan pasokan dari oelabuhan } \\
\text { Ratu dan Cilacap / Supply has been } \\
\text { coming from Pelabuhan Ratu and } \\
\text { Cilacap }\end{array}$ \\
\hline $\begin{array}{l}\text { Biaya perolehan bahan baku/ } \\
\text { Cost of Input }\end{array}$ & \multicolumn{2}{|c|}{$\begin{array}{l}\text { Mengalami peningkatan }>20 \% \text {, karena menggunakan transportasi darat dari } \\
\text { Pelabuhan Ratu dan Cilacap ke Jakarta (Untuk Tuna) / Has been rising as } \\
\text { much as } 20 \% \text { due to using land transport from Pelabuhan Ratu and Cilacap }\end{array}$} \\
\hline
\end{tabular}

Sumber: Data Diolah/ Source: Data Processed

\section{PENUTUP}

Efektivitas kebijakan moratorium terhadap kinerja usaha dapat disimpulkan sebagai berikut:

1. Bagi pelaku usaha perikanan tangkap skala besar dinilai kurang efektif karena telah berdampak pada penurunan produksi hasil tangkapan, pemberhentian nelayan $\mathrm{ABK}$, pengeluaran biaya tambahan dan biaya operasional, menurunnya omzet pelaku usaha pendukung usaha perikanan. Bagi usaha penangkapan skala kecil cukup berdampak positif karena terjadi kenaikan produksi hasil tangkapan, meningkatnya biaya operasional terutama untuk pengadaan bahan baku UPI, peningkatan pendapatan nelayan tradisional.

2. Bagi pelaku usaha pengolahan, kebijakan yang diimplementasikan dinilai kurang efektif baik baik usaha pengolahan skala kecil maupun skala besar. Bagi usaha pengolahan skala besar, telah berdampak pada pengurangan produksi olahan ikan, pemberhentian tenaga kerja olahan dan terganggunya ekspor ikan olahan ke luar negeri.

\section{DAFTAR PUSTAKA}

Anonim. 2014. Peraturan Menteri Kelautan dan Perikanan No. 56/2014. KKP. Jakarta

Anonim. 2015. Tindak Lanjut Terhadap Kapal Perikanan Indonesia Yang Pembangunannya Dilakukan Di Luar Negeri Dan Ikan Hasil Tangkapan Yang Tersimpan Dalam Colo Storage Atau Palkah/Refigerator Kapal. Surat Edaran Nomor: 581/Sj/ Ps.210n11112015. KKP. Jakarta

Damanik, R., Suhana, dan B. Prasetiamartati. 2008. Menjala Ikan Terakhir (Sebuah Fakta Krisis di Laut Indonesia). Jakarta: WALHI 
Jaelani, A. Q. dan B. Udiyo. Illegal Unreported and Unregulated (IUU) Fishing: Upaya Mencegah dan Memberantas Illegal Fishing dalam Membangun Poros Maritim Indonesi. SUPREMASI HUKUM. Vol. 3, No. 1, Juni 2014

Marlyna, dan F. Riza. 2013. Aspek Hukum Peran Masyarakat dalam Mencegah Tindak Pidana Perikanan, (Jakarta: PT. SOFMEDIA, 2013), p. 1.

Nasution, S. 2006. Metode Research Penelitian Ilmiah. Jakarta: Bumi Aksara.

Nazir, M. 1988. Metode Penelitian . Ghalia Indonesia. Jakarta. Halaman 222.
Sitorus, M. T. F. 1998. Penelitian Kualitatif Suatu Pengantar. IPB. Bogor

Sunyowati, D. 2014. Dampak Kegiatan luu-Fishing Di Indonesia Departemen Hukum Internasional Fakultas Hukum-Universitas Airlangga . Disampaikan pada Seminar Nasional " Peran dan Upaya Penegak Hukum dan Pemangku Kepentingan Dalam Penanganan dan Pemberantasan IUU Fishing di Wilayah Perbatasan Indonesia". Kerjasama Kementerian Luar Negeri Republik Indonesia dengan Universitas Airlangga Surabaya, 22 September 2014. 